\title{
Rooftop Turbine Ventilator: A Review and Update
}

\author{
Mazran Ismail ${ }^{1} \&$ Abdul Malek Abdul Rahman ${ }^{1}$ \\ ${ }^{1}$ School of Housing, Building \& Planning, Universiti Sains Malaysia, Penang, Malaysia \\ Correspondence: Mazran Ismail, School of Housing, Building \& Planning, Universiti Sains Malaysia, 11800 \\ Penang, Malaysia. Tel: 60-12-463-1134. E-mail: mazran@usm.my
}

Received: February 13, 2012 Accepted: April 5, 2012 Online Published: May 1, 2012

doi:10.5539/jsd.v5n5p121

URL: http://dx.doi.org/10.5539/jsd.v5n5p121

The research is financed by Universiti Sains Malaysia (USM) through its Research Creative Management Office (RCMO)

\begin{abstract}
As an alternative to air-conditioning systems, the rooftop turbine ventilator now is not only widely accepted as industrial ventilation, but also has become a common ventilation feature used in other types of buildings including institutional, commercial and residential. Although it is often thought to be very effective even in the lightest wind conditions, but many scientific studies found that its actual performance in the real building is not very promising due to some outdoor climatic constraints and the weaknesses of the device's configuration itself. Therefore, in order to describe its full characteristics, reliability, limitations and possible improvement of the device, this paper discusses the current development and future prospects of the turbine ventilator by elaborating the results of some experimental and analytical work that have been done in various aspects of its application and performance. The analysis and summarized findings presented in this paper also recommend some criteria that should be considered in designing future turbine ventilator which is not only ventilate well in high-wind speed region, but also could be an effective multifunction device even in low wind velocity region.
\end{abstract}

Keywords: turbine ventilator, wind-driven ventilation, solar energy, energy efficiency

\section{Introduction}

Due to the simple operating mechanism and relatively affordable price, a turbine ventilator which is driven by natural wind force is always a preferred choice to ventilate the building without depending on air conditioning system which is usually associated with global warming, finite fossil energy depletion and sick building syndrome (SBS) (Seppanen \& Fisk, 2002; Liping \& Hien, 2007). This device, which is also known as a rotary ventilator is a wind-driven air extractor which was originally patented by Meadows since 1929. It is considered as one type of roof ventilator which has been defined by American Society of Heating, Refrigerating and Air-Conditioning Engineers (ASHRAE) (1999) as 'a heat escape port located high in a building and properly enclosed for weather tightness with the primary motive forces being stack effect and wind induction'. Due to these characteristics, the rooftop turbine ventilator can be categorized as both active and passive ventilation strategy.

Dominantly, turbine ventilator is classified as an active ventilation strategy although it does not use any electricity to rotate. This is due to the fact that the constantly moving spinning blades driven by outdoor wind force is found to be the major factor that creates centrifugal forces in the turbine, which in turn extract hot air from the building (Khan et al., 2008). On the other hand, the turbine ventilator could also be considered as a passive ventilation strategy, especially in the absence of wind. This is due to the existence of net free vent area i.e. openings between vertical blades which can induce stack effect and extract hot and stale air out from the building if there is sufficient indoor-outdoor temperature differential (Rudd \& Lstiburek, 1998). Because of these rationales, the turbine ventilator can be classified as wind-assisted stack ventilation or wind-stack driven ventilation strategy as termed by Allard (1998) since it can maximize both wind-induced and stack effect to extract hot and stale air from the building.

In general, the device composes a waterproof frame which is mounted by a number of vertical vanes in a spherical or cylindrical array and a base duct which is connected by a shaft and bearings. Today, after eight decades since it was first extensively commercialized by Edmonds of Australia in 1931 for the purpose of industrial ventilation, the device now is very well accepted and has become a common ventilation feature used in various types of buildings including institutional, commercial and residential (Ahmed, 2010). Although it is often thought to be effective 
even in the lightest wind conditions as low as $1.5 \mathrm{~m} / \mathrm{s}$ (Edmonds, 2007), many academic studies found that its actual performance in the real building is not very promising due to some outdoor climatic constraints and the weaknesses of the device's configuration itself. Therefore, in order to describe its full characteristics, reliability and limitations of its current development as well as possible enhancement of the device, the following section will discuss the experimental and analytical work on the performance of turbine ventilator which has been done before.

\section{Experimental and Analytical Work on the Performance of Turbine Ventilator}

Among the earliest discussions on the turbine ventilator principle and performance were contained in the reports by Savonius (1932) and Back (1932) who published experimental results comparing cowls and the S-rotor wind driven fan (Revel \& Huynh, 2004). Apart from these very early works, there are only a few published work on the device that can be found before the new millennia. These include a few pattern reports and a study by Dale and Ackerman (1993) on the performance of conventional attic turbine ventilators. However, in the last decade, turbine ventilator applications have attracted many attentions in various types of investigation, which can be categorized into three main aspects i.e. its application strategy \& performance parameters, effect of configuration variables \& modifications and different research tools \& methods.

\subsection{Turbine Ventilator Application and Performance Parameters}

Studies on rooftop turbine ventilator applications and functions have been expressed in terms of conventional use of turbine ventilator in different types of building and a combination of turbine ventilator with extractor fan system. The outcome results of its performance were discussed in terms of (i) ventilation rate (in 1/s, $\mathrm{m}^{3} / \mathrm{s}, \mathrm{ACH}$ and $\mathrm{CMH}$ ) (ii) air velocity $(\mathrm{m} / \mathrm{s})$ (iii) air temperature (reduction) $\left({ }^{\circ} \mathrm{C}\right)$. Dale and Ackerman (1993), Mihailov, Dinchev, Vlaseva, Petrov, and Tenev (2003), Lai (2003) and Cox et al. (2011) studied the effectiveness of conventional type of rooftop turbine ventilators applied in different types of building and under different climatic conditions. On the other hand, Porfirio (2004) and Kuo and Lai (2005) investigated the effect of combining the turbine ventilator with electrical extractor fan ventilation system.

In one of the earliest academic studies on the real application of turbine ventilator, Dale and Ackerman (1993) investigated the effectiveness of the 12 " $(305 \mathrm{~mm})$ diameter turbine ventilator in improving attic ventilation of a house already installed with two soffit vents of $0.08 \mathrm{~m}^{2}$ free vent areas. The study showed that in the US temperate climate and windy condition, the turbine ventilator could reduce the attic temperature by only $0.56^{\circ} \mathrm{C}$ and increased ventilation rates by $15 \%$ from $5.3 \mathrm{ACH}$ to $6.1 \mathrm{ACH}$ on average as compared to the existing condition of the test house. The study also concluded that the ventilation enhancements by the device were a function of wind direction with the best being wind with more upwind shelter.

Lai (2003) studied the effectiveness of conventional wind-driven turbine ventilator application in factories and residences under the windy condition of Taiwan. The study indicated that the use of the device is helpful to increase ventilation rate $(\mathrm{CMH})$, thus enhance natural stack ventilation. However, for the zero to low-wind velocity condition, the study revealed that the turbine itself blocked the airflow in the connecting pipeline/duct, thus creating a lower ventilation rate even compared to the condition when there was no ventilator at all.

In temperate climate of South Africa, Cox et al. (2011) studied the possibility of using turbine ventilator to increase ventilation performance that in turn could reduce Tuberculosis (TB) transmission risk in four primary care clinic rooms. Using $\mathrm{CO}_{2}$ gas tracer technique to assess the efficacy of the wind-driven roof turbines and air-intake grates combination to achieve recommended ventilation rates, the study showed that such installation succeeded to induce higher median $\mathrm{ACH}$ compared with natural cross ventilation strategy. It also achieved to exceed the level of $60 \mathrm{l} / \mathrm{s}$ per patient as recommended by World Health Organization (WHO) for 95\% or more of measurements in 3 out of 4 rooms, while the measurement in another one room indicated the result of $47 \%$ complying with that standard due to the relatively low wind speed and smaller size of turbine ventilator installed as compared to the previous three rooms.

On the other hand, Porfirio (2004) conducted a study to investigate the performance of a combined turbine ventilator and electric fan in inducing air change rate $(\mathrm{ACH})$ on a greenhouse under the temperate climate of Brazil. The study revealed that turbine ventilator assisted by inner fan is capable to increase the ventilation rate from 9 $\mathrm{ACH}$ to $11 \mathrm{ACH}$ as compared to only 0 to $5 \mathrm{ACH}$ if turbine ventilators were forced only by natural wind.

Kuo and Lai (2005) investigated the ventilation performance of the conventional turbine ventilator combined with bathroom ventilation system equipped with extractor fan under the tropical climate of Taiwan. The results showed that such combination was successful to achieve sufficient air change rate in bathroom, thus improved its indoor air quality. The study also concluded that the induced negative pressure resulted from the combining system helped to reduce leakage of odors and moisture to other interior spaces of the building. 


\subsection{Turbine Ventilator Configurations and Modifications}

Studies on impact of configuration variables on turbine ventilator performance have been expressed in terms of turbine diameter (size), blade height, blade configuration, openings and duct/throat diameter. On the other hand, some experimental studies on the modifications of turbine ventilator have been done by combining it with inner extractor fan and with lightpipe for lighting purpose.

i) Size - Several studies were concerned with the impact of diameter (size) variables of turbine ventilators on its ventilation performance. Based on the wind tunnel and field study results under Taiwan climate conditions, Lai (2003) confirmed the consumer beliefs that the bigger size of turbine ventilator would induce higher ventilation rate. However, it was found that the ventilation rate induced by more commonly used ventilators of $14 "(360 \mathrm{~mm})$ and $20 "(500 \mathrm{~mm})$ are more or less the same, meaning that the rate can be considered equal when it comes to the application in engineering.

ii) Blade Height - Study on the effect of vane or blade height on turbine ventilator performance was carried out by West (2001). By conducting an experimental study on Long Volume Turbines (LVTs) as shown in Figure 1 , the study found that $13.5 \%$ improvement in flow rate could be achieved if the vane/blade height is increased by $50 \%$. This is based on the results which showed that when turbine ventilators of different vane heights of 170 , 250 and $340 \mathrm{~mm}$ were tested at a fixed wind speed of $12 \mathrm{~km} / \mathrm{h}$, it would induce different airflow rates of 65,70 and $751 /$ s, respectively.

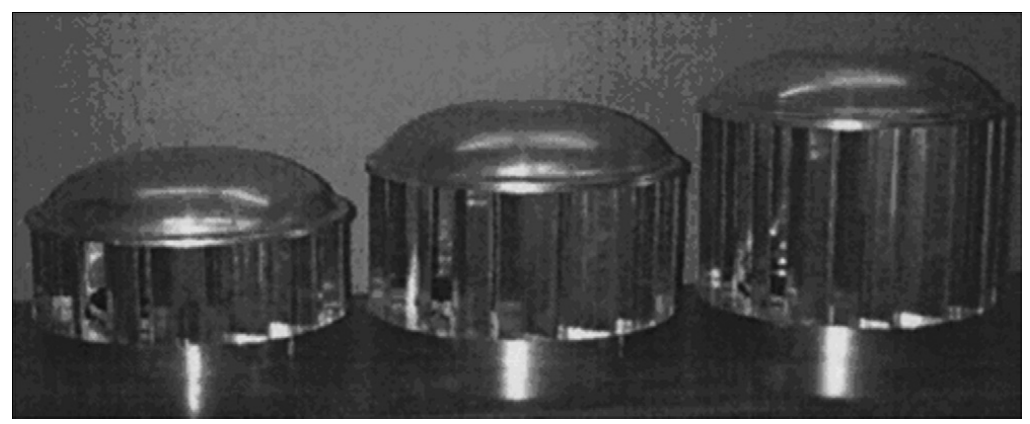

Figure 1. Variable blade height/LVTs

Source: West, 2001.

iii) Blade Design (curved or straight vane) - In terms of vertical vane or blade design, Khan, Su, Riffat and Biggs (2008) found that for the same size of 300mm (12") turbine ventilator, the curved vane type of ventilator had about $25 \%$ larger flow rate than the straight vane ventilator at the same wind speeds. Besides, the study on the different types and forms of turbines ventilator as shown in Figure 2 also revealed that the fabrication material of the device also affect the ventilator's capacity to induce airflow.

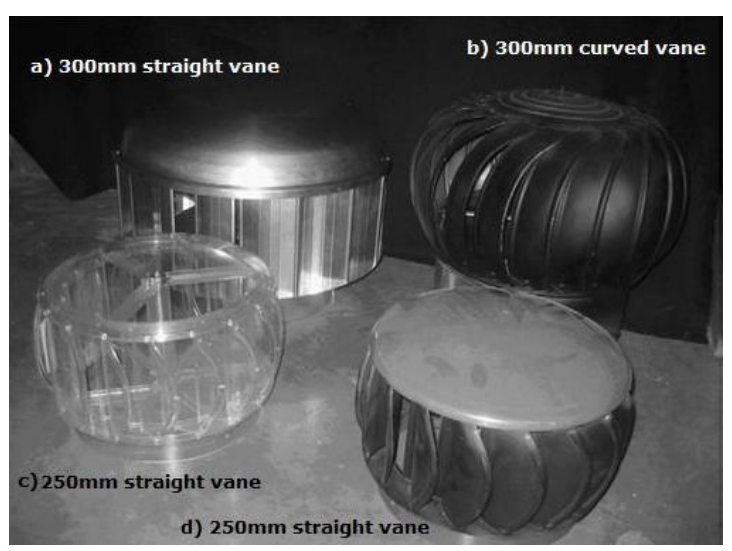

Figure 2. Different types of turbine ventilators under test (a) $300 \mathrm{~mm}$ straight vane turbine (b) $300 \mathrm{~mm}$ curved vane turbine (c) $250 \mathrm{~mm}$ straight vane turbine (d) $250 \mathrm{~mm}$ straight vane turbine

Source: Khan et al., 2008. 
iv) Throat Diameter and Opening - On the other hand, Revel and Huynh (2004) investigated the impact of different sizes (diameter) of turbine ventilator's throat or duct on air extraction rates. The results of a single performance curve (embodying air extraction rates, wind speeds, throat size and pressure differentials across the devices) confirmed that the turbine ventilator with bigger throat of $300 \mathrm{~mm}$ (12") is perform better than turbine ventilator with $250 \mathrm{~mm}$ (10") diameter throat. The study also indicated that the simple open stub (without turbine ventilator) performed best in air extraction, thus recommended the type to be a base-line model for improving conventional turbine ventilator (Figure 3).

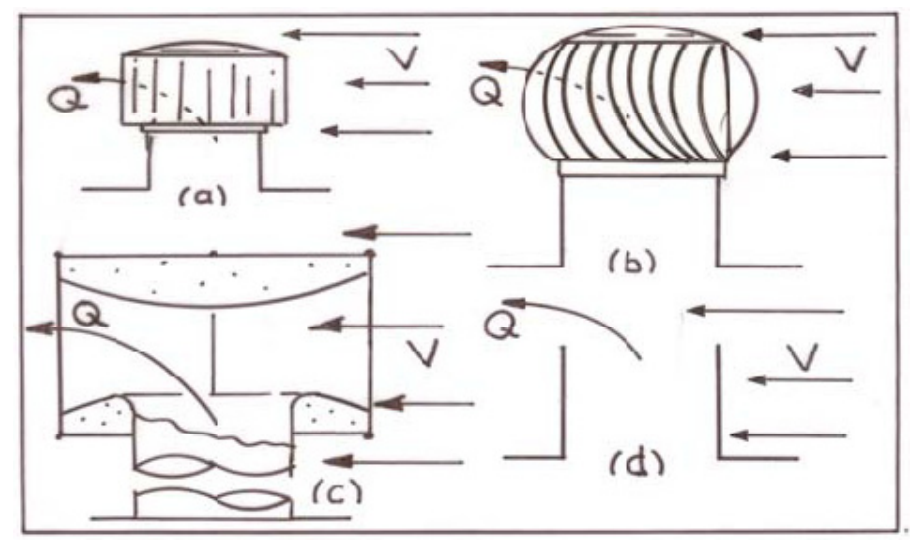

Figure 3. Diagram of the four ventilating devices (eductors) tested; (a) $250 \mathrm{~mm}$ throat turbine type, (b) $300 \mathrm{~mm}$ throat turbine type, (c) $300 \mathrm{~mm}$ throat omni directional venturi, (d) $300 \mathrm{~mm}$ bore open stub

Source: Revel \& Huynh, 2004.

v) With Inner Vane - The experimental study by Lai (2003) on the impact of installing inner vane inside the frame of turbine ventilator has confirmed that the added element can help the device to exhaust better. However, the study concluded that the availability of inner vanes inside the turbine ventilator sized 20" (500mm) and 14" $(360 \mathrm{~mm})$ do not mark significant differences in the ventilation rate induced. According to Lai (2003), structural factors in the flow and the imperfect shapes of the inner rotating vanes could be the major factors limiting its performance, which should be taken into consideration when designing a new model of the turbine ventilator.
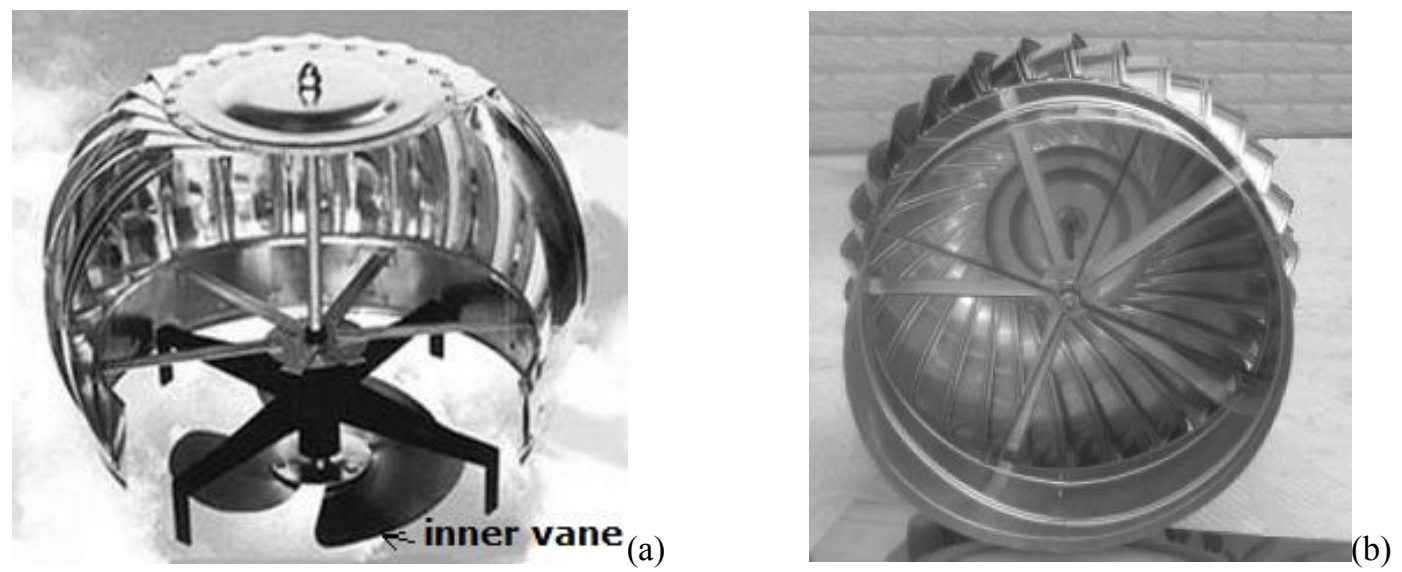

Figure 4. Typical configuration of turbine ventilator (a) with inner vane (b) without inner vane

vi) With Extractor Fan - In ensuring the reliability of the turbine ventilator operation in low-wind velocity condition, one of the most strategies that seem promising is by combining a wind-driven turbine ventilator and solar-powered extractor fan, as shown in Figure 5(a). The prototype 20" $(500 \mathrm{~mm})$ hybrid solar-wind turbine ventilator developed by Lai (2006) by replacing the existing inner vane with 16 " (400mm) PV powered DC inner fan showed that it succeeded to increase the ventilation rate $\left(\mathrm{m}^{3} / \mathrm{s}\right)$, especially with a rated rotation speed of 
$1500 \mathrm{rpm}$ and at low outdoor wind speed of up to $5 \mathrm{~m} / \mathrm{s}$. However, in high outdoor wind speed condition, the study showed that the evaluation indicator (inner fan enhancement) was negative; meaning that raising the inner fan rotational could reduce the ventilation fraction. The study also suggested that for the best performance of the device in Taiwan building and factory, the optimum power of PV panels should be 74.76W, charge controller is $3.2 \mathrm{~A}(24 \mathrm{~V}), 10.35 \mathrm{Ah}$ at 24 battery for one day storage and at least one dc/ac inverter.

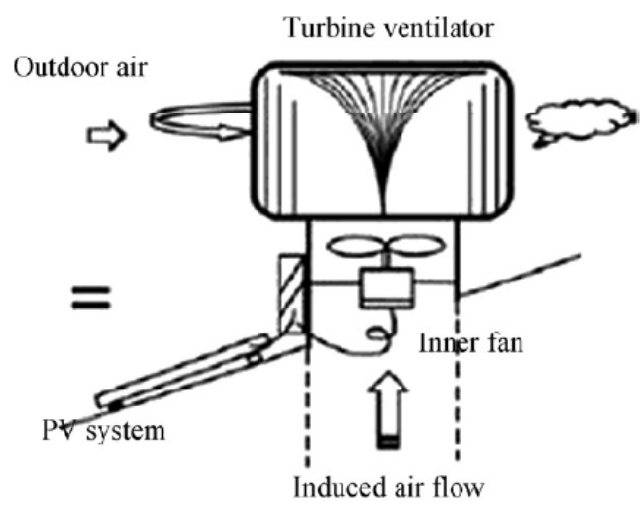

(a)

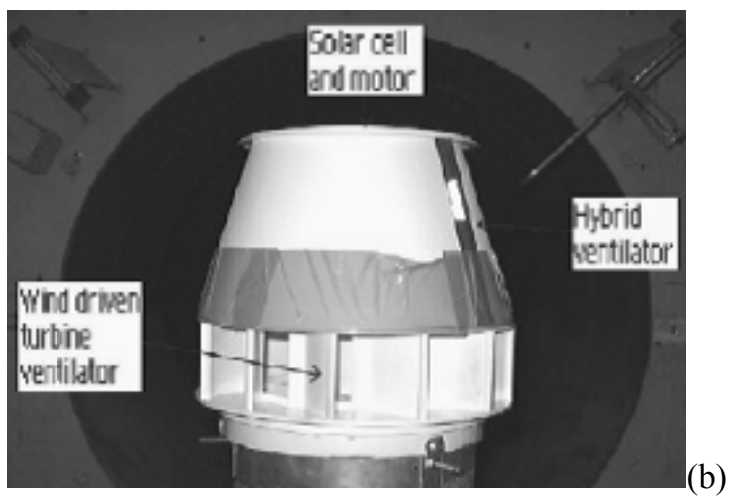

Figure 5. Hybrid PV-Wind Powered Turbine Ventilator (a) Illustrative diagram of the prototype device developed by Lai (2006), (b) Full-scale model developed by Shun and Ahmed (2008)

On the other hand, Shun and Ahmed (2008) also developed a hybrid PV-wind turbine ventilator but the main intention is to maximize free flow of air in the absence of sunlight by placing the motor-fan at the upper part of the turbine (Figure 5(b)). In line with Lai's (2006) result, this study revealed that such combination showed better performance compared to conventional wind driven turbine ventilator, especially at zero to low wind speeds. Investigating the performance of this hybrid solar-wind driven turbine ventilator in the real building and under real Malaysian climate condition, Ismail and Abdul Rahman (2010) found that such device with larger free outlet area on top of the turbine and inner duct with extractor fan located at ceiling level as shown in Figure 6(a) achieved to reduce indoor air temperature by $0.7^{\circ} \mathrm{C}$ in the occupied level.
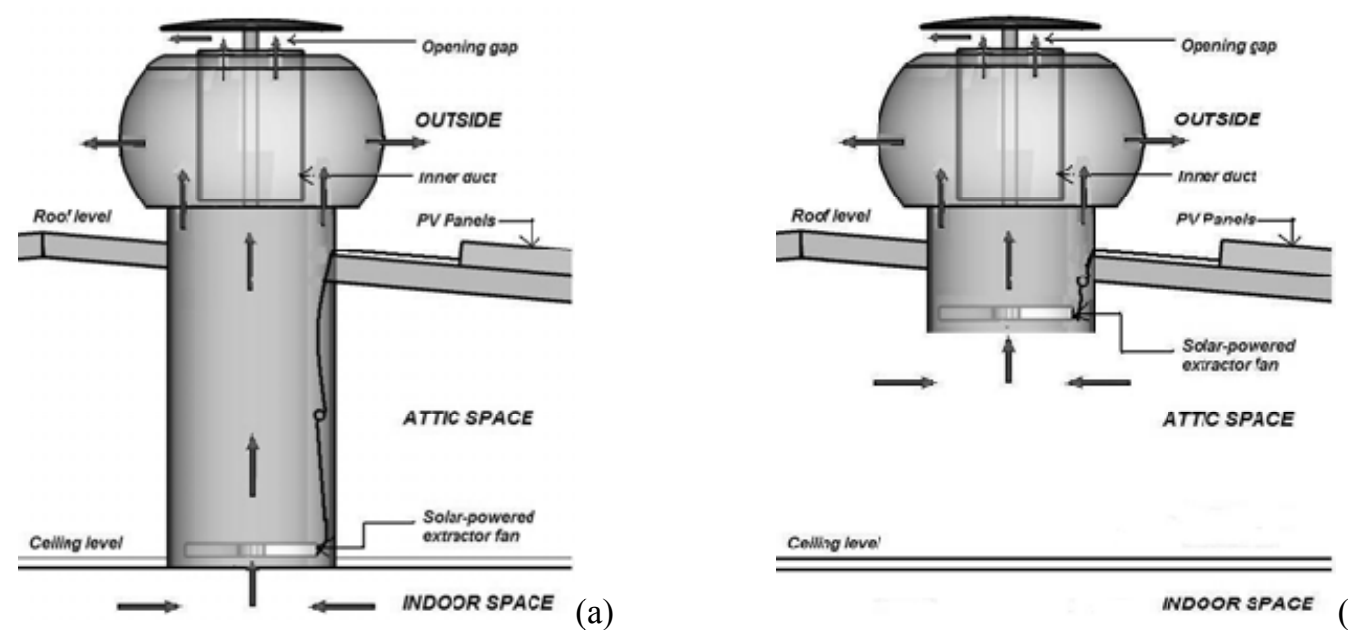

Figure 6. Illustrative diagram of the Hybrid Turbine Ventilator with inner duct and larger upper outlet area for occupied space (left) and attic space (right)

Source: Ismail \& Abdul Rahman, 2010

In Taiwan, Shieh et al. (2010) carried out both field study and computational fluid dynamic simulations to assess and estimates the indoor ventilation induced by the hybrid turbine ventilator for the model factory. The findings 
revealed that the innovative device as has been developed by Lai (2006) succeeded to extract indoor air approximately four times greater than the exhaust capacity of a conventional turbine ventilator.

vii) With Lightpipe - In another innovative development, Zain-Ahmed et al. (2007) investigated the potential of the prototype hybrid ventilator that combined conventional turbine ventilator with lightpipe to increment both ventilation and daylighting level inside the building (Figure 7). Based on the laboratory study, the prototype has shown promising results especially with the use of two units of solar powered inner fan, a controller, 3 units of battery and a DC motor. However, the study indicated that the air velocity $(\mathrm{m} / \mathrm{s})$ induced is much less than the minimum velocity needed for occupants' thermal comfort in the building under hot-humid climate of Malaysia.

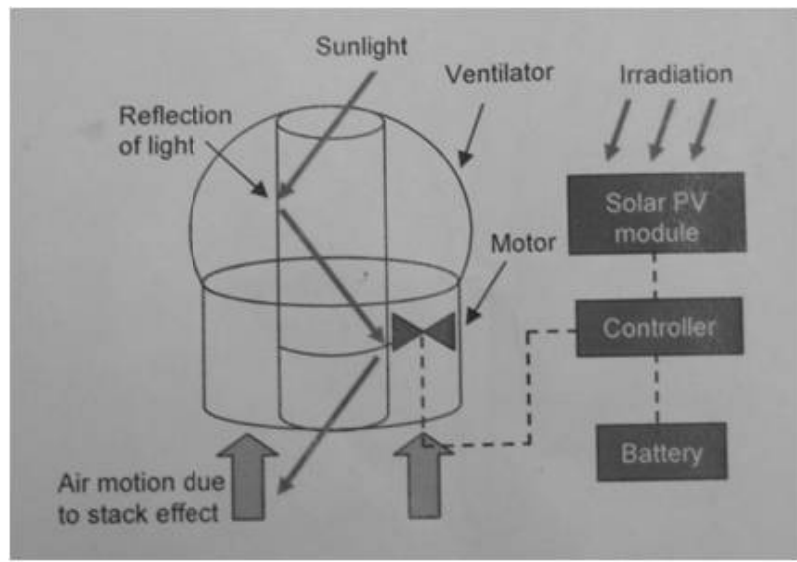

Figure 7. Illustrative diagram of the novel Photovolatic Lighting Ventilation (PVLV)

Source: Zain-Ahmed et al., 2007

\subsection{Turbine Ventilator and Research Tools}

Studies on turbine ventilator performance have been investigated by both qualitative and quantitative methods, which involved various research tools. Example of qualitative method is by conducting airflow visualization study to investigate the pattern of the airflow through the turbine ventilator. On the other hand, quantitative methods includes the techniques that utilize an experimental set-up or laboratory study, wind tunnel study, full-scale field measurement study and also by a numerical method, including the study which utilize the use of Computational Fluid Dynamic (CFD) simulations to assess and estimate the ventilation performance of the turbine ventilator.

West (2001), Revel and Huynh (2004), Zain-Ahmed et al., (2007), Khan et al. (2008) and Shun and Ahmed (2008) use a set of turbine ventilator test rigs which usually comprising plenum chamber, variable speed supply fan and large wind producing fan with flow straighteners, balancing chamber with flow metering and sensitive manometer, and anemometer as a measurement tool. The major aim of all these studies is to investigate the airflow rate (ventilation rate) of different configurations of turbine ventilator at varying outdoor wind speeds.

Lai (2003) used low-speed wind tunnel experiment to acquire the common operation mode of the application of turbine ventilators in Taiwan and to investigate the effect of different turbine sizes and the existence of inner vane on its performance. The study also involved a flow visualization study by using the Gas-Tracing Technology which the final result succeeded to show the clearer patterns of horizontal flows in the turbine ventilator. From this visualization study, it was observed that when the air flowed through the ventilator, it split into two streams which are:

i) One flow was in the direction of rotation and thus became the motive force for rotation

ii) The other flow was in the opposite direction of rotation and dampened the ventilator rotation.

Based on this observation, Lai clarified that the rotating blades threw the extracted air away to mix into these two wind airflows, which converged in the wake region on the opposite side of the incident wind. Figure 8 visualized both the horizontal and vertical airflow structure during the turbine ventilator's operation. 

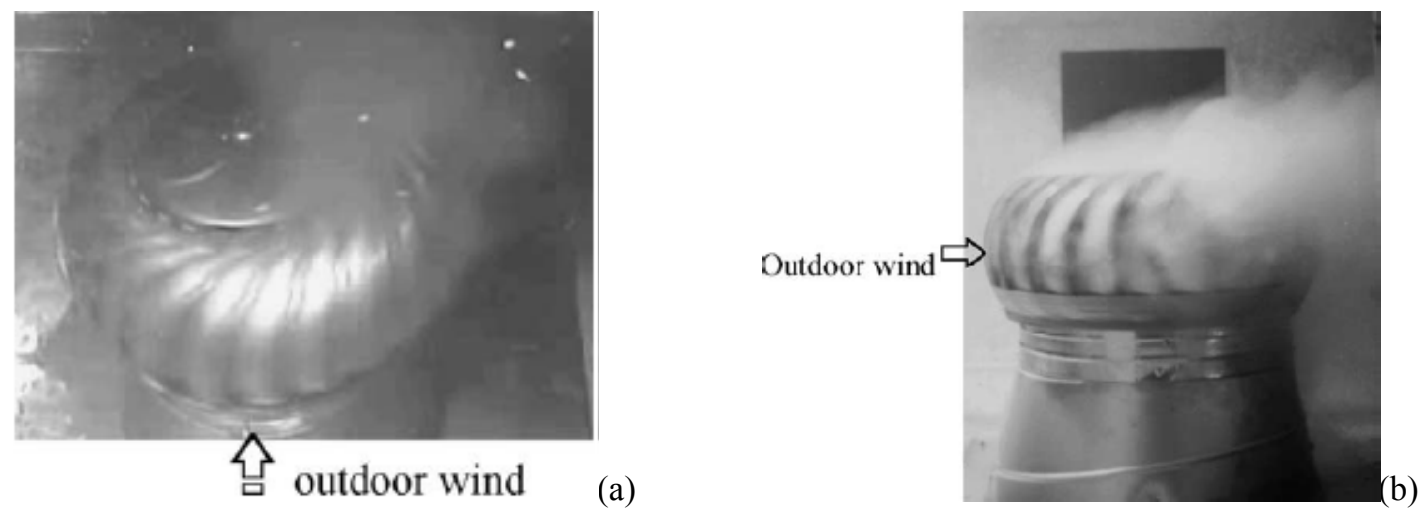

Figure 8. Visual of airflow during the operation of turbine ventilator (a) Horizontal flow structure (b) Vertical flow structure

Source: Lai, 2003

The wind tunnel study to investigate the aerodynamic forces and complex airflow associated with this turbine ventilator has also been carried out by Rashid and Ahmed (2003). Conducting an experiment in the aerodynamic laboratory with the use of a simple physical model of both spinning and stationary cylinders, the study succeeded to provide qualitative information on aerodynamic force acting on the device and also on the airflow nature and its relation to drag force components. Regarding the turbine ventilator's blades, the results revealed that in high wind velocity condition, more partial flow separation was induced on that component, thus urged for significant improvement in the blade's future design to ensure its efficiency over a larger velocity range (Rashid \& Ahmed, 2003; Lien \& Ahmed, 2010).

Another wind tunnel study on the performance of the device was performed by Kuo and Lai (2005) to evaluate the overall ventilation performance of installing a turbine ventilator to an existing duct ventilation system, which serves fourteen bathrooms in Taiwan. For this study, the multi-functional ventilation detector, which is equipped with two sensing connectors, was used to measure and detect a variety of environmental factors such as wind speed, temperature and humidity. On the other hand, the study also involved a full-scale field measurement study. The ventilation rates of the roof turbine ventilator and bathroom ceiling fans were measured using the multi-point measurement method for the HVAC (heating, ventilating, and air-conditioning) duct. Measurements for each controlled different condition lasted three days and the sampling rate of the airflow velocity was set at $10 \mathrm{~s}$ intervals. Evaluating the results based on Hygienic Risk Indicator, the study found that there was hygienic risk only when the turbine ventilator was out of order and the bathroom ceiling fans were off. In contrast, the condition of when turbine ventilator is freely rotating and ceiling fans is on showed the best ventilation performance.

Following the study, Lai (2006) and Shun and Ahmed (2007) performed another wind tunnel studies to investigate the ventilation performance of the prototype ventilator that combined PV-powered extractor fan with wind-driven turbine ventilator. By using the dual-loop experimental procedure of the low-speed wind tunnel test, Lai (2006) investigated several parameters like flow structures, induced ventilation rate, pressure difference and operation technique during the prototype development of the device. On the other hand, based on the results of the study done in aerodynamics laboratory, Shun and Ahmed (2007) stressed that the installed fan did not improve the ventilation rate of the device when the outdoor wind velocity is more than $5.0 \mathrm{~m} / \mathrm{s}$, since the ventilation mechanism of the turbine ventilator was absolutely dominated by the outdoor airflow.

Apart from the field study conducted by Kuo and Lai (2005) as mentioned earlier, Dale and Ackerman (1991), Porfirio (2004) and Ismail and Abdul Rahman (2010) also used a full scale field measurement study to investigate the actual performance of the device under the real climate conditions which the results are already discussed in the previous sub-section.

In contrast with previously mentioned physical experimental methods, Havens (2004) used a numerical study by developing simple mathematical method to model the attic turbine ventilator (ATV) simultaneously as a fan and as wind turbine so that the wind speed can be related to fan airflow for varying rotational speeds. The study found that the correlation is dependent on knowing the co-efficiency of power and torque for a given attic turbine ventilator. With these coefficients, wind speeds and the system characteristic curve for an attic, attic ventilation rate changes can be accurately predicted based on attic turbine ventilator performance independent of other mechanical or natural ventilation forces (Havens, 2004). 
On the other hand, numerical studies which utilize the use of Computational Fluid Dynamic (CFD) simulations have been done by Farahani et al. (2010), Shieh et al. (2010) and Lien and Ahmed (2010; 2011). Farahani et al. (2010) used FLUENT CFD simulation software to visualize the airflow behavior inside and around the turbine ventilator as well as to determine the aerodynamic forces acting on the device during its rotation. The findings ensured that the CFD method which employed k- model and The Reynold's stress model (RSM) is reliable to be used in investigating the performance of the turbine and in designing its future configuration and model.

Using PHOENIC CFD software to simulate the steady-state airflow and temperature distributions, Shieh et al. (2010) compared the ventilation efficiency of several configurations and installation positions of both hybrid solar-wind powered turbine ventilator and conventional ventilator. The simulation study revealed that the hybrid turbine ventilator (HTV) is 4 times greater in terms of ventilation rate compared with conventional one, while the central position of the HTV on slanted rooftop is found to be the optimum placement of the device, indicating $0.5 \mathrm{~m} / \mathrm{s}$ higher air velocity compared with its placement near the roof ridge.

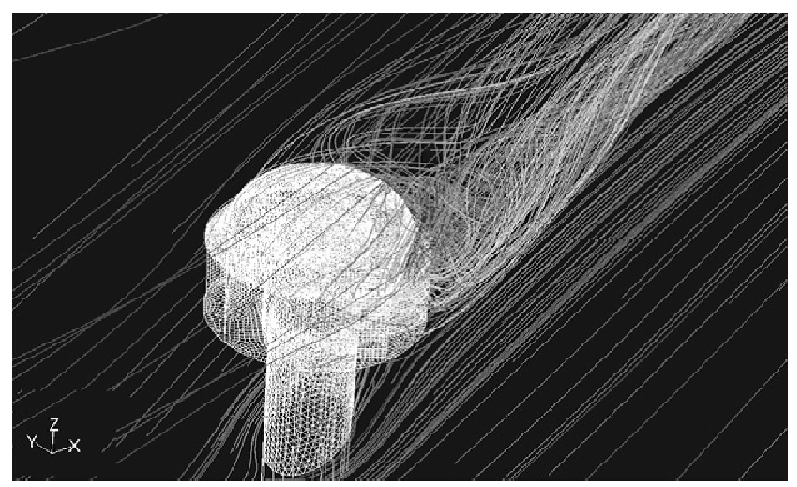

Figure 9. 3-dimensional path line of the airflow associated with the straight vane turbine ventilator during its operation at $10 \mathrm{~m} / \mathrm{s}$

Source: Lien \& Ahmed, 2010

In another numerical simulation study as shown in Figure 9, Lien and Ahmed (2010) have employed the standard k- turbulence model with multiple reference frames (MRF) meshing technique to investigate the suitability of numerical method in modeling various features of a turbine ventilator flow. By examining both the external and internal flows associated with turbine ventilator at various wind velocity and assessing the ventilation performance of a rotating turbine ventilator, the CFD study showed that the trend observed is parallel with the published data. Thus, the results clearly indicate that numerical simulation could be a feasible and affordable tool in analyzing the performance and designing prototype development of the turbine ventilator.

In the most recent study, Lien and Ahmed (2011) used computer simulation to investigate the effect of roof inclination angle on the performance of wind driven turbine ventilator. The results revealed that with the increasing in inclination angle of the roof, the total force acting on the turbine ventilator will be decreased, thus significantly reducing the rotational speed of the device, especially at high wind velocity condition. This is mainly due to the increasing of skin friction resulted from the increasing in inclination angle has retarded the free wind flow, which in turn has reduced the force acting on the turbine ventilator. Considering this factor, the study suggested that the inclined roof can be a helpful strategy to extend the safety margin of the turbine ventilator operation in high wind velocity condition, due to the fact that it can lessen the magnitude of the total force acting on the device (Lien \& Ahmed, 2011).

\section{Discussion}

From the literature reviews, it is confirmed that there are several factors affecting the rooftop turbine ventilator performance. This includes the factors of configuration and application strategy of the device itself, roof inclination angle, building form \& room layout and the natural surrounding factors like ambient outdoor condition and typology of the site.

In terms of configuration, previous experimental and theoretical research works conducted on the performance of turbine ventilator have indicated that optimum configuration of the device is mainly determined by the form and 
size of the turbine, length and diameter of ducting and the effect of its integration with other devices like axial fan and lightpipe. The summarized results are shown in Table 1.

Table 1. Summary of previous research on optimum configurations of turbine ventilator

\begin{tabular}{|c|c|c|}
\hline Configuration & Description & References \\
\hline $\begin{array}{l}\text { Size } \\
\text { (turbine diameter) }\end{array}$ & $\begin{array}{l}\text { The bigger size induced higher ventilation rate, } \\
\text { but do not mark significant effect between 14" } \\
\text { and } 20 \text { " diameter size of turbine ventilator }\end{array}$ & $\begin{array}{l}\text { Lai (2003), Ravel \& } \\
\text { Huynh (2005), Khan et } \\
\text { al. (2008) }\end{array}$ \\
\hline $\begin{array}{l}\text { Height } \\
\text { (turbine height) }\end{array}$ & $\begin{array}{l}\text { Increasing } 15 \% \text { in height could improve } 13.5 \% \\
\text { in air flow rate }\end{array}$ & West (2000) \\
\hline $\begin{array}{l}\text { Fan blade (curved or } \\
\text { straight vane) }\end{array}$ & $\begin{array}{l}\text { The curved vane ventilator induced } 25 \% \text { larger } \\
\text { air flow rate than the straight vane }\end{array}$ & Khan et al. (2008) \\
\hline Duct diameter & $\begin{array}{l}\text { The larger size of throat/diameter of the duct } \\
\text { could induced higher ventilation rate }\end{array}$ & Revel \& Huynh (2005) \\
\hline With inner vane & $\begin{array}{l}\text { The availability of inner vane do not mark } \\
\text { significantly differences in the ventilation rate } \\
\text { induced }\end{array}$ & Lai (2003) \\
\hline With extractor fan & $\begin{array}{l}\text { Integration with extractor fan could ensure its } \\
\text { consistency and induced much higher ventilation } \\
\text { rate, but only optimum in low outdoor wind } \\
\text { condition of not more than } 5 \mathrm{~m} / \mathrm{s}\end{array}$ & $\begin{array}{l}\text { Kuo \& Lai (2005), Lai } \\
(2006) \text {, Shun \& Ahmed } \\
(2007) \text {, Khan et al. } \\
(2008) \text {, Ismail \& Abdul } \\
\text { Rahman (2010), Shieh et } \\
\text { al. (2010) }\end{array}$ \\
\hline With lightpipe & $\begin{array}{l}\text { Integration with lightpipe could provide } \\
\text { daylighting, but limits the effective size/diameter } \\
\text { of the turbine which in turn reduces the } \\
\text { ventilation rate }\end{array}$ & Zain-Ahmed et al. (2007) \\
\hline
\end{tabular}

Based on Table 1, it can be concluded that for the conventional type of turbine ventilator, the resulted ventilation rate, air change rate $(\mathrm{ACH})$ and air velocity induced by the device are found to be very dependent on outdoor wind condition. To overcome this problem, the strategy of combining it with solar-powered extractor fan as have been developed by Lai (2006), Shun and Ahmed (2007), Zain-Ahmed et al. (2007), Ismail and Abdul Rahman (2010) and Shieh et al. (2010) seems to be the most appropriate strategy to ensure its consistency and reliability in the low-wind velocity region. Furthermore, it is expected that the performance of this strategy could significantly be enhanced if the entire optimum configurations listed in Table 1 are taken into consideration in developing a new turbine ventilator model.

\section{Conclusion}

Based on the previous experimental and analytical work that have been done in various aspects of rooftop turbine ventilator application and performance, this paper has elaborated the full characteristics, current status and also the possible development of the device for the coming future. The previous studies which involve physical measurement and CFD numerical simulation methods have discussed many important aspects of the device, including the clarification of the actual airflow patterns inside and outside the device, its typical ventilation performance in relation with different configurations as well as the actual applicability of the turbine ventilator in the real building and under real climate conditions. Some of the recent studies also confirmed that the hybrid turbine ventilator (HTV) which can maximize both free energy from the sun and outdoor wind could be a more potent and reliable alternative compared to conventional ones in ensuring higher rotation rate and its consistency in low-wind velocity region. Based on the analyses and summarized findings, this paper has also suggested some criteria, current limitations and future prospects of the device which need to be considered in developing future 
design of rooftop turbine ventilator which is not only ventilate well even in low wind speed region, but also could be a simple yet effective multifunction device.

\section{Acknowledgements}

The authors would like to thank Universiti Sains Malaysia (USM) and its Research Creative Management Office (RCMO) for the financial support provided for this research work.

\section{References}

Ahmed, N. A. (2010). Wind-Solar driven natural electric hybrid ventilators. In S. M. Muyeen (Ed.), Wind power (pp. 537-558). Croatia: InTech. http://dx.doi.org/10.5772/8349

Allard, F. (1998). Natural ventilation in buildings: A design handbook. London: James \& James.

American Society of Heating, Refrigerating and Air-Conditioning Engineers (ASHRAE). (1999). ASHRAE Handbook: HVAC Applications. Atlanta: American Society of Heating, Refrigerating, and Air-Conditioning Engineers, Inc. (S28.20)

Cox, H., Escombe, R., McDermid, C., Mtshemla, Y., Spelman, T., Azevedo, V., \& London. L. (2011). Wind-Driven Roof Turbines: A Novel Way to Improve Ventilation for TB Infection Control in Health Facilities. PLoS ONE, 7(1), e29589, 1-6. http://dx.doi.org/10.1371/journal.pone.0029589

Dale, J. D., \& Ackerman, M. Y. (1993). Evaluation of the performance of attic turbine ventilators. ASHRAE Transactions, 99(1), 14-22.

Edmonds. (2007). Roof space ventilation. Retrieved from http://www.edmonds.com.au/Products/

Farahani, A. S., Adam, N. M., \& Ariffin, M. K. A. (2010). Simulation of airflow and aerodynamic Forces Acting on a Rotating Turbine Ventilator. American Journal of Engineering and Applied Sciences, 3(1), 159-170. http://dx.doi.org/10.3844/ajeassp.2010.159.170

Havens, P. (2004). A combined fan and wind turbine model for attic turbine ventilators. Energy Efficient and Healthy Buildings, ARE 318-E.

Ismail, M., \& Abdul Rahman, A. M. (2010). Comparison of different hybrid turbine ventilator (HTV) application strategies to improve the indoor thermal comfort. International Journal of Environmental Research, 4(2), 297-308.

Khan, N., Su, Y., \& Riffat, S. (2008). A review on wind-driven ventilation techniques. Energy and Buildings, 40, 1586-1604. http://dx.doi.org/10.1016/j.enbuild.2008.02.015

Khan, N., Su, Y., Riffat, S., \& Biggs, C. (2008). Performance testing and comparison of turbine ventilators. Renewable Energy, 33, 2441-2247. http://dx.doi.org/10.1016/j.renene.2008.01.016

Kuo, I. S., \& Lai, C. M. (2005). Assessment of the potential of roof turbine ventilators for bathroom ventilation. Building Services Engineering Research and Technology, 26(2), 173-179. http://dx.doi.org/10.1191/0143624405bt123tn

Lai, C. M. (2003). Experiments on the ventilation efficiency of turbine ventilators used for building and factory ventilation. Energy and Buildings, 35, 927-932. http://dx.doi.org/10.1016/S0378-7788(03)00024-0

Lai, C. M. (2006). Prototype development of the rooftop turbine ventilator powered by hybrid wind and photovoltaic energy. Energy and Buildings, 38, 174-180. http://dx.doi.org/10.1016/j.enbuild.2005.06.004

Lien, S. T. J., \& Ahmed, N. A. (2010). Numerical simulation of rooftop ventilator flow. Building and Environment, 45(8), 1808-1815. http://dx.doi.org/10.1016/j.buildenv.2010.02.009

Lien, S. T. J., \& Ahmed, N. A. (2011). Effect of inclined roof on the airflow associated with a wind driven turbine ventilator. Energy and Buildings, 43, 358-365. http://dx.doi.org/10.1016/j.enbuild.2010.09.027

Lien, J., \& Ahmed, N. A. (2010). Wind driven ventilation for enhanced indoor air quality. In N. Mazzeo (Ed.), Chemistry, Emission Control, Radioactive Pollution and Indoor Air Quality (pp. 539-562). Croatia: InTech.

Liping, W., \& Hien, W. N. (2007). The impacts of ventilation strategies and facade on indoor thermal environment for naturally ventilated residential buildings in Singapore. Building and Environment, 42, 4006-4015. http://dx.doi.org/10.1016/j.buildenv.2006.06.027

Meadows, V. H. (1929). Rotary ventilator. US Patent 1,857,762.

Mihailov, M., Dinchev, Z., Vlaseva, E., Petrov, T., \& Tenev, I. (2003). Forcing of natural ventilation in electrolytic shops. Annual Mining and Mineral Processing, Sofia, 46, Part II, 147-152. 
Porfirio, R. (2004). The uses of rotary turbine ventilator for controlling the air temperature and ventilation in greenhouse. Retrieved from http://www.teses.usp.br/teses/

Rashid, D. M. H., \& Ahmed, N. A. (2003). Study of Aerodynamic Forces on a Rotating Wind Driven Ventilator. Wind Engineering, 27(1), 63-72. http://dx.doi.org/10.1260/030952403321833770

Revel, A., \& Huynh, B. P. (2004). Characterizing roof ventilators. Paper presented at The $15^{\text {th }}$ Australasian Fluid Mechanics Conference, 13-17 December, The University of Sydney, Australia.

Rudd, A. F., \& Lstiburek, J. W. (1998). Vented and sealed attics in hot climates. ASHRAE Transactions, 104(2), 1199-1210.

Seppanen, O., \& Fisk, J. (2002). Association of ventilation system type with SBS symptoms in office workers. Indoor Air, 12, 98-112. http://dx.doi.org/10.1034/j.1600-0668.2002.01111.x

Shieh, T. H., Chang, P. C., Chiang, C. M., \& Lai, C. M. (2010). Potential assessment of an innovative hybrid ventilator for building ventilation. Journal of Mechanical Science and Technology, 24(11), 2341-2345. http://dx.doi.org/10.1007/s12206-010-0809-2

Shun, S., \& Ahmed, A. N. (2008). Utilizing wind and solar energy as power sources for a hybrid building ventilation device. Renewable Energy, 33, 1392-1397. http://dx.doi.org/10.1016/j.renene.2007.07.017

West, S. (2001). Improving the sustainable development of building stock by the implementation of energy efficient, climate control technologies. Building and Environment, 36, 281-289. http://dx.doi.org/10.1016/S0360-1323(00)00007-X

Zain-Ahmed, A., Shaari, S., Omar, A. M., \& Ahmed, S. (2007). The PVLV: A new generation hybrid ventilator. Paper presented at PECIPTA 2007, 1-12 August 2007, Universiti Teknologi MARA (UiTM), Malaysia. 